\title{
Article \\ Effects of an Information and Communication Technology-Based Fitness Program on Strength and Balance in Female Home Care Service Users
}

\author{
Sonja Jungreitmayr ${ }^{1, *}$, Susanne Ring-Dimitriou ${ }^{1} \mathbb{D}$, Birgit Trukeschitz ${ }^{2} \mathbb{D}$, Siegfried Eisenberg ${ }^{2}$ \\ and Cornelia Schneider ${ }^{3}$ (D)
}

1 Department of Sport and Exercise Science, Paris Lodron University of Salzburg, 5400 Hallein-Rif, Austria; susanne.ring@sbg.ac.at

2 Research Institute for Economics of Aging, Vienna University of Economics and Business, 1020 Vienna, Austria; Birgit.Trukeschitz@wu.ac.at (B.T.); siegfried.eisenberg@gmail.com (S.E.)

3 Institute of Computer Science, University of Applied Sciences Wiener Neustadt, 2700 Wiener Neustadt, Austria; Cornelia.Schneider@fhwn.ac.at

* Correspondence: sonja.jungreitmayr@sbg.ac.at; Tel.: +43-699-11015339

\section{check for}

updates

Citation: Jungreitmayr, S.; Ring-Dimitriou, S.; Trukeschitz, B.; Eisenberg, S.; Schneider, C. Effects of an Information and Communication Technology-Based Fitness Program on Strength and Balance in Female Home Care Service Users. Int. J. Environ. Res. Public Health 2021, 18 7955. https://doi.org/10.3390/ ijerph18157955

Academic Editor: Paul B. Tchounwou

Received: 24 June 2021

Accepted: 23 July 2021

Published: 28 July 2021

Publisher's Note: MDPI stays neutral with regard to jurisdictional claims in published maps and institutional affiliations.

Copyright: (C) 2021 by the authors. Licensee MDPI, Basel, Switzerland. This article is an open access article distributed under the terms and conditions of the Creative Commons Attribution (CC BY) license (https:// creativecommons.org/licenses/by/ $4.0 /)$

\begin{abstract}
There is evidence that training for strength and balance prevents decline in physical function in old age when the training is personally instructed. It is an open question whether interventions that deliver training via up-to-date technologies can achieve long-term effects. This study examined the effects of an 8-month fitness training program delivered via information and communication technology (ICT) on lower-body strength and balance in female home care users $(n=72)$ aged 75 years on average. For statistical analysis, the test group was divided into two subgroups, one who used the program at least 8 times per month $(n=26)$ and another one who used the program less often $(n=17)$ compared with a control group that received no exercise program $(n=29)$. It was found that regular ICT-exercisers exhibited positive effects over time on lower-body strength and balance compared to a decrease in both indicators in irregular exercisers and the control group. The authors see potential in offering exercise programs to people of advanced age via ICT to counteract physical decline in old age.
\end{abstract}

Keywords: exercise; function/mobility; assistive technology; assisted living

\section{Introduction}

Staying functionally fit, which means having the physical capacity to perform motor tasks safely, independently, without excessive stress in everyday life, is vital for independent living, especially among older adults [1]. Exercise programs that address different components of physical fitness, such as strength as well as balance, prevent the deterioration of physical functions in old age [2]. Evidence-based general recommendations on physical activity (PA) for older adults suggest integrating regular endurance, strengthening, balance, and flexibility exercises into the weekly exercise program, whereas training for strength should be completed at least twice per week [3-6].

Most interventions that promote physical activity in older adults are carried out under personal supervision and guidance, which ties up a large number of resources per case [7]. However, there is evidence that positive effects on strength and balance can be achieved when movement interventions are carried out without supervision [8]. Modern technologies can easily transport unsupervised training and are becoming more available, creating new opportunities in terms of reducing costs and economic burden and improving the quality of life for people as they age [7,9].

While the current literature finds positive effects in short-term information and communication technology (ICT)-based interventions to promote physical activity in people between 55 and 80 years of age [7], there is a need for further research in specific user 
groups regarding long-term effects using state-of-the-art technologies. One user group growing larger is that of older persons in need of assistance. According to recent WHO data, $14 \%$ of all people over the age of 60 lack functional ability in daily living [10]. A closer look at home care service users (HCSU) shows that, within this population, women live longer with impaired quality of life than men [11]. Gender differences are also noticeable, with women needing more assistance with activities of daily living in later life than men, due to their lack of strength [8]. Women within this population are also more likely to fear falling, which is associated with impaired balance ability [12]. Because both strength and balance ability are critical for independent living later in life in women, the effects of novel training on these markers should be specifically investigated.

There is thus evidence that ICT-assisted training can promote physical activity in older people in general [7] and that this is particularly important in women [11]. Furthermore, there are also recommendations to use comprehensive devices for promoting physical activity [13]. Likewise, it can be considered certain that supervised functional training can have positive effects on physical status in older women [12,14-16]. Nevertheless, over the long term, to the best of our knowledge, there is still no evidence whether unsupervised functional training delivered via ICT has a positive effect on the development of strength and balance in older women with mild assistance needs.

Therefore, the purpose of this study was to examine the effects of an ICT-guided functional fitness program on strength and balance of female HCSUs who were on average 75 years old, over eight months, and to analyze whether following the recommended exercise frequency makes a difference. In this context, we hypothesize that unsupervised, functional ICT-supported fitness training will have positive effects on strength and balance outcomes in female HCSUs when performed at least twice a week, compared to lower usage or no access to the ICT-program at all.

\section{Materials and Methods}

\subsection{Study Design}

The group studied in this paper is the subset of female HCSUs targeted in the CiM project (Care-in-Movement), which aimed to develop an ICT-enabled care support system for HCSUs and their environment. In this project, a parallel group design with matched pairs was conducted on male and female HCSUs in Austria and Northern Italy [17]. This design is a very focused recruitment method that closely resembles a fully randomized controlled trial design [18]. From an available data set of participants who met predefined eligibility criteria (age between 55 and 85 years, no cognitive impairments, no more than low limitations in hearing and/or vision, and/or defined limitations in mobility), individuals were randomly selected for the intervention group and matched for the control group. The recruitment started after this preparation. In order to comply exactly with all the required specifications, the recruiters were obliged to follow a detailed protocol [17].

HCSUs assigned to the test group (TG) received an ICT-based intervention. The intervention consisted of a functional fitness program (FFP) with daily alternating 10-min training sessions delivered via a specially designed tablet application and lasted 8 months [19]. The participants assigned to the control group (CG) had no access to the ICT-based intervention.

\subsection{Data Collection}

All study participants in both countries were offered to be tested three times in their homes by their caregivers, at baseline ( $\mathrm{t} 0)$, after 6 months ( $\mathrm{t} 1)$, and at the end ( $\mathrm{t} 2$ ) of the trial period. The test at $\mathrm{t} 1$ was scheduled after six months to ensure a possible change in physical activity level [20], and thus to expect effects on strength and balance. The final test (t2) was conducted to ensure impact analysis over the full eight-month period. A total of 109 female HSCUs showed up on all three occasions.

The care workers collected data with standardized equipment. System usage data needed for grouping and adherence evaluation were collected by a logging component (Matomo, InnoCraft, 150 Willis St., Wellington, New Zealand) [19]. 


\subsection{Intervention: ICT-Supported Functional Fitness Program (FFP)}

After the experts had assigned an appropriate exercise difficulty and intensity level, the software compiled an order of exercises based on the workout structure (see Table 1). For this purpose, the exercises were stored in a hidden library within the tablet and sorted by category. The "Joint Mobility Exercises" category contained simple movements such as arm circles, which involved moving through the joints without loading. Exercises for the upper extremity and spine joints were labeled "Joint Mobility Exercises 1," and those for the lower extremity and spine were labeled "Joint Mobility Exercises 2." The "Coordination Exercises" consisted of complex movements-such as circling the arms while marching on the spot. The "Balance Exercises" included variations of the one-legged stand such as leg-swings and tandem stand, with or without holding onto the back of a chair, depending on the exercise difficulty selected. Finally, the category "Strengthening Exercises" included motor tasks that stressed the entire body or upper body (Strengthening Exercises 1) and the lower body (Strengthening Exercises 2), such as table push-ups, extending the knees while sitting, lifting the heels while standing, lunges with or without holding on to a chair back. The exercises in the training sessions were delivered visually, with short video clips, and vocally, with simple explanatory text in the local language via the tablet app. To maintain adherence of ICT-program users, the exercises changed daily, providing variety and attractiveness. The training sessions were kept as short as possible, lasting on average $10 \mathrm{~min}$, following the general recommendations [3-5]. Every session consisted of six bodyweight-bearing exercises (see Table 1).

Table 1. Order of Main Motor Abilities Addressed in a 10-min Workout Routine.

\begin{tabular}{|c|c|c|c|}
\hline \multicolumn{4}{|c|}{ Workout Routine-Structure } \\
\hline \multirow{4}{*}{ WarmUp } & Joint Mobility Exercise 1 & Set 1 & $40 \mathrm{~s}$ \\
\hline & Joint Mobility Exercise 2 & Set 1 & $40 \mathrm{~s}$ \\
\hline & Joint Mobility Exercise 1 & Set 2 & $40 \mathrm{~s}$ \\
\hline & Joint Mobility Exercise 2 & Set 2 & $40 \mathrm{~s}$ \\
\hline \multirow{4}{*}{ Coordination } & Coordination Exercise & Set 1 & $40 \mathrm{~s}$ or $8-12$ reps \\
\hline & Balance Exercise & Set 1 & $40 \mathrm{~s}$ \\
\hline & Coordination Exercise & Set 2 & $40 \mathrm{~s}$ or $8-12$ reps \\
\hline & Balance Exercise & Set 2 & $40 \mathrm{~s}$ \\
\hline \multirow{4}{*}{ Strength } & Strengthening Exercise 1 & Set 1 & $8-12$ reps \\
\hline & Strengthening Exercise 2 & Set 1 & $8-12$ reps \\
\hline & Strengthening Exercise 1 & Set 2 & $8-12$ reps \\
\hline & Strengthening Exercise 2 & Set 2 & $8-12$ reps \\
\hline
\end{tabular}

Note. This figure shows the structure of a $10 \mathrm{~min}$ session. Duration per exercise is indicated either in seconds $(=\mathrm{s})$ or repetitions (=reps).

After a warm-up phase containing joint mobility exercises, the main part of each session included exercises for both coordination as well as strength. The volume for each coordination exercise was set at two sets for $40 \mathrm{~s}$ per set [21]. Strength training was set at two sets per exercise in a repetition range from 8 to 12 repetitions per set to initiate adaptations [22]. This methodology ensured that people who chose to do the exercise program at least two times a week would have reached the minimum dose for a neuromotor stimulus for increased balance as well as strength [23].

\subsection{Measures}

\subsubsection{Anthropometric Data}

Body height in $\mathrm{m}$ and body mass in $\mathrm{kg}$ were measured both accurate to a tenth with a mobile stadiometer (Seca 213, Seca GmbH, Hamburg, Germany) and a digital 
scale (Smartlab scale W, HMM Diagnostics GmbH; Heddesheim, Germany) according to standardized procedures [24]. Body Mass Index $\left(\mathrm{BMI}=\mathrm{kg} / \mathrm{m}^{2}\right)$ was calculated as body mass in kilograms divided by height in squared meters, again accurate to a tenth [24].

\subsubsection{Overall Strength-Grip Strength (GRIP)}

Grip strength, which is a useful tool for screening older adults for risk of future health deterioration as well as a potent surrogate measure for overall strength, was tested with a hand-dynamometer (Deyard EH101, Deyard Technology Ltd., Shenzhen, China) [25,26].

HSCUs were asked to sit upright on a chair, both feet planted on the ground, hipwidth apart, one arm hanging loosely on the body side, the other arm positioned on a desk plate, bent at 90 degrees. The hand-dynamometer was then placed in a neutral grip position into the hand, resting on the counter. Then, the handle had to be squeezed without changing posture. The assessment was conducted in an alternating fashion for a total of three repetitions per hand. The mean of all repetitions from both sides was calculated. Results were measured to the nearest tenth of a kilo [27].

\subsubsection{Lower-Body Strength-30s Chair Rise (30CR)}

The 30 s Chair Rise test indicates lower-body strength among older communitydwelling adults [28]. All trial participants were asked to sit upright on a chair without using the backrest. Foot position had to be at hip-width. Arms were crossed over the chest with the hands touching the contralateral shoulder. The proper execution of the task was examined before starting the testing procedure. After checking for readiness, the command 3-2-1-go was applied, and the completed repetitions within $30 \mathrm{~s}$ were recorded. If the participant ended up standing at the lapse of the $30 \mathrm{~s}$ timeframe, this was counted as 0.5 repetitions. The results were recorded to the nearest half repetition.

\subsubsection{Balance-Uni-Pedal-Stance (UPS)}

UPS is a valid measure of static balance [29]. All trial participants were asked to place the hands on their hips and focus on an imaginary spot on the eye-level at the wall, right opposite to them. The test ended when the position was exited via (1) lowering the lifted leg onto the ground, (2) twisting the ground-based foot to stay in balance, (3) lifting the arms off the hips, and (4) pressing the lifted leg onto the ground-based leg or if the person could stand one-legged for over $60 \mathrm{~s}$. This was applied in alternating fashion up to six trials in total, three for each leg. The best score of all trials of both legs was included in the evaluation to the nearest tenth of a second.

\subsection{Sample}

Female participants enrolled in CiM $(N=124)$ provided the basis for our evaluation. Female participants who participated in all tests at each time point $(\mathrm{t} 0, \mathrm{t} 1, \mathrm{t} 2)$ were included in this data analysis (see Figure 1) and further subdivided by adherence for statistical analyses.

Adherence is defined here as active participation in the intervention program. To measure this participation, automatically logged usage data were used [19]. Usage data gives insights about which components of the app were used, how often they have been used and when they have been used. Schneider (2020) utilized this information to build sub-groups based on the usage frequency of the system. The smallest unit in this measuring framework was a "visit". A "visit" started with the first use of the system on a new day or after a pause of at least $30 \mathrm{~min}$. To be counted as "adhered to" an exercise screen had to be on for $30 \mathrm{~s}$ or longer. This timespan was based on the time used for one training set $(40 \mathrm{~s}$ or 8 to 12 reps; see Table 1). User groups were then formed, based on visits that contained adhered exercises. Frequent users did use the training program at least 8 times per months, regular users between 4 and 7 times per month, infrequent users adhered between 1 and 3 times per months and people who never used the exercise program were grouped into non-users [19]. 


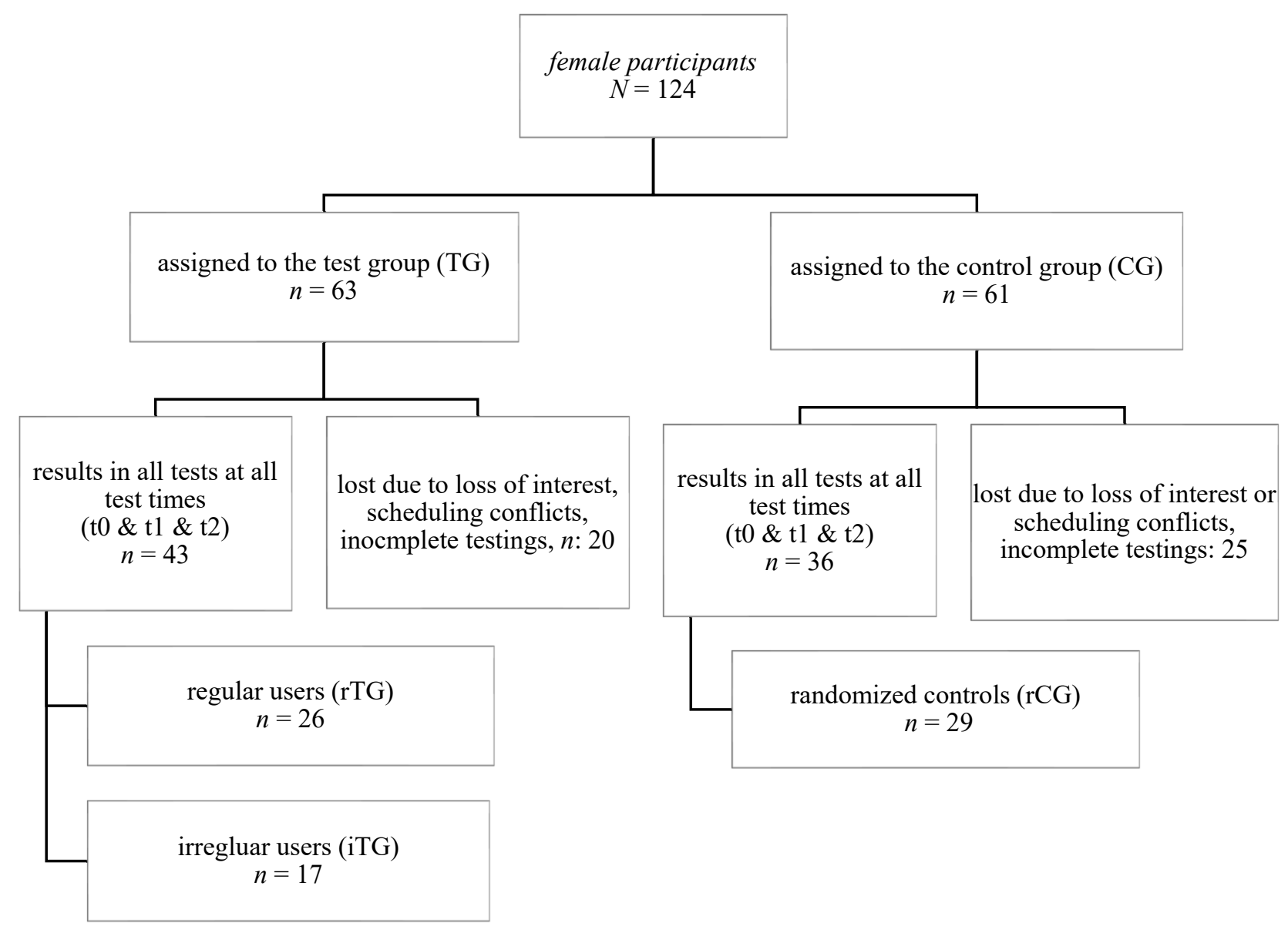

Figure 1. Flow of Participants Regarding Division Into Evaluation Groups/regular users used the system $>8$ times per month, irregular users used it less than 8 times per month.

Since the minimum dose for a neuromotor stimulus to increase balance as well as lower body strength is two times per week [23], we recombined these groupings for the study of effects on markers of strength, and balance. The rTG included all subjects who were classified as regular users in the usage data analysis, i.e., who had used the program at least eight times per month and thus showed sufficient adherence. The remaining groups were combined as the irregular test group (iTG), as these usage frequencies do not indicate sufficient adherence. To avoid low power due to unequal sample sizes, we selected $n=29$ participants of the CG (rCG) by the random number function in SPSS for the comparison between sub-groups [30].

\subsection{Statistical Analysis}

Statistical analysis was carried out using SPSS (version 27.0; IBM Corp., Armonk, NY, USA). Baseline data were described with mean \pm standard deviation. To check whether anthropometry was an influencing factor of the outcome variables and thus had to be considered as a covariate, a correlation analysis, using Pearson's correlation coefficient $r$, was calculated [31].

To evaluate the effects over time and between groups, the first step was to test for normal distribution using Shapiro-Wilk's test. Normally distributed data, which also did not violate Levene's test for equality of variances, were analyzed by analysis of variance (ANOVA) to compare the characteristics of the subgroups with respect to these variables, at each test date. If significant differences between subgroups were found, pairwise comparisons were performed using the Scheffe procedure [32]. To account for possible 
baseline differences in the effects between groups and over time, an ANCOVA adjusted for baseline values, was calculated.

Nonparametric methods were chosen to examine the effects between groups and over time of data that did not follow the normal distribution assessed by the Shapiro-Wilk test or violate Levene's test for equality of error variances. The Kruskal-Wallis $\mathrm{H}$ test was executed to assess differences at times between subgroups [33]. Changes over time within subgroups were analyzed via the Friedman test, respectively [34]. Results were reported accordingly, with median or median rank values. If statistically significant differences between subgroups were detected, pairwise comparisons using Dunn's procedure with a Bonferroni correction for multiple comparisons were performed [35]. After performing the nonparametric test, a repeated measures nonparametric analysis of covariance (ANCOVA) was run [36]. As groups vary in size, the Scheffe procedure was chosen to serve as post hoc test [32].

The level of significance was set to $p<0.05$. Adjusted $p$-values are presented. Effect sizes are expressed as Pearson's $r$ in the Kruskal-Wallis H as well as the Friedman test and as $\eta p^{2}$ in ANOVA as well as ANCOVA, whereas $r$ is considered to be a relatively small effect at 0.1 , typical at 0.2 and relatively large at 0.3 [37] and $\eta p^{2}$ is defined to be a small effect at 0.01 , moderate at 0.06 and large at 0.14 [38].

\section{Results}

\subsection{Basline Data}

Table 2 shows baseline characteristics of subgroups in descriptive measures. On average, the female HCSUs were aged $75.5( \pm 7.6)$ years $(n=72)$ with a mean BMI of $29.2( \pm 6.4)$ thus should be categorized as overweight to obese [39]. Bonferroni post hoc analysis revealed that the iTG had higher BMI $+4.9,95 \% \mathrm{CI}(3,9.5)$ than $\mathrm{rTG}$, which was statistically significant $(p=0.034)$ as well as rCG $+5.5,95 \%$ CI $(1.0,10.0)$ which also was a significant difference $(p=0.012)$, but no other group differences were statistically significant regarding BMI. Given that BMI is a potential confounder of the functional markers [40,41], the correlation of BMI with the outcome variables was calculated. Since Pearson's $r$ showed no correlations between BMI and outcome variables at all test time points, BMI was not included as a covariate in follow-up calculations.

Table 2. Baseline Characteristics of Sub-Groups.

\begin{tabular}{|c|c|c|c|c|c|c|}
\hline \multirow[t]{2}{*}{ Descriptives } & \multicolumn{2}{|c|}{$\begin{array}{c}\text { rTG } \\
n=26\end{array}$} & \multicolumn{2}{|c|}{$\begin{array}{c}\text { iTG } \\
n=17\end{array}$} & \multicolumn{2}{|c|}{$\begin{array}{c}\text { rCG } \\
n=29\end{array}$} \\
\hline & $M$ & $S D$ & $M$ & $S D$ & $M$ & $S D$ \\
\hline Age, yrs & 74.4 & 6.8 & 75.5 & 7.4 & 76.6 & 8.5 \\
\hline Height, cm & 158.4 & 7.7 & 159.2 & 7.5 & 160.8 & 6.3 \\
\hline Weight, kg & 71.7 & 18.5 & 84.5 & 21.3 & 71.5 & 15.6 \\
\hline BMI, $\mathrm{kg} / \mathrm{m}^{2}$ & 28.3 & 5.1 & 33.2 & 7.3 & 27.7 & 6.0 \\
\hline GRIP, kg & 20.7 & 6.1 & 17.4 & 5.7 & 17.6 & 5.7 \\
\hline $30 \mathrm{CR}, \mathrm{cts}$ & 10.5 & 6.2 & 8.5 & 3.3 & 5.6 & 5.6 \\
\hline UPS, s & 13.8 & 17.1 & 10.7 & 11.4 & 9.7 & 16.0 \\
\hline
\end{tabular}

Note. rTG = regular users; iTG = irregular users; rCG = randomized controls.

As Table 2 and Figure 2 show, the results of the first measurement indicate insufficient or poor fitness of the participants compared to normative values in terms of grip strength, lower-body strength, and static balance ability regardless of subgroup [29,42,43]. This means that the trial participants started at a below average functional fitness level. 


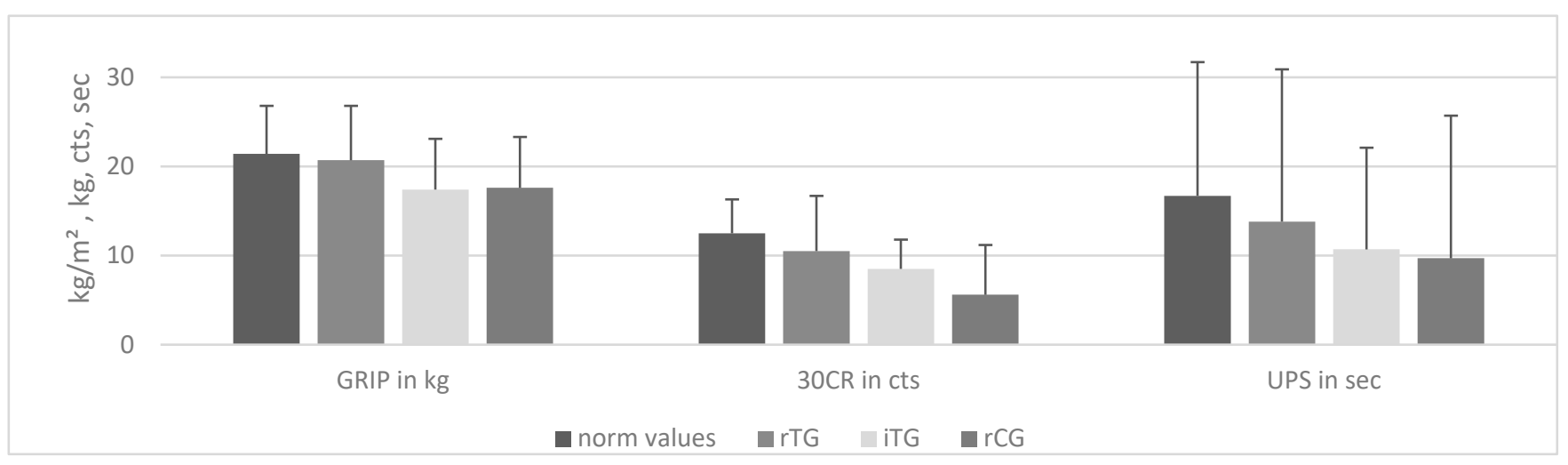

Figure 2. Comparison of Baseline Results With Gender- and Age-Specific Norm Values/This figure shows the baseline data of the subgroups compared to correspondingly matching norm values. GRIP = grip strength; 30CR = 30 s Chair Rise test; UPS = Uni Pedal-Stance. Data presented as mean (incl. SD one-sided) in kg = kilogram, cts $=$ counts or sec $=$ seconds. $r T G=$ regular users; iTG = irregular users; $\mathrm{rCG}=$ randomized controls.

\subsection{Adherence}

A total of 124 females attended at least one of three tests ( $t 0, t 1$, and $t 2)$. Forty-three females belonged to the TG, received the intervention, and were present at all tests. Thirtysix females belonged to the CG and were present at all tests (see Figure 1). The TG was, as stated before, divided into regular (rTG; usage rate $\geq 8 \mathrm{x} / \mathrm{month}$ ) and irregular (iTG; usage rate $<8 \mathrm{x} /$ month) users. $60 \%$ of the TG who attended all three test sessions used the system regularly in this way and could be attributed to the rTG. The remaining TG participants who were present at all test sessions used the system 1 time per week or less, i.e., irregularly, and were therefore assigned to the iTG.

\subsection{Effects on Grip Strength Measured by GRIP}

While there is no significant difference within groups regardless of subgroup as well as between groups at baseline and $\mathrm{t} 2$, ANOVA shows a highly significant difference between groups at $\mathrm{t} 1$ (see Table 3 ).

Table 3. Differences in GRIP Between Groups at Times.

\begin{tabular}{|c|c|c|c|c|c|c|c|c|c|}
\hline \multirow{2}{*}{ GRIP, kg } & \multicolumn{2}{|c|}{$\begin{array}{c}\text { rTG } \\
n=26\end{array}$} & \multicolumn{2}{|c|}{$\begin{array}{c}\text { iTG } \\
n=17\end{array}$} & \multicolumn{2}{|c|}{$\begin{array}{c}\text { rCG } \\
n=29\end{array}$} & \multicolumn{3}{|c|}{ ANOVA } \\
\hline & $M$ & $S D$ & $M$ & $S D$ & $M$ & $S D$ & $\begin{array}{c}F \\
(2 / 69)\end{array}$ & $p$ & $\eta^{2}$ \\
\hline t0_GRIP_mean & 20.7 & 6.1 & 17.4 & 5.7 & 17.6 & 5.7 & 2.411 & 0.097 & 0.065 \\
\hline t1_GRIP_mean & 21.1 & 6.6 & 16.5 & 5.7 & 16.9 & 4.6 & 5.088 & 0.009 & 0.129 \\
\hline t2_GRIP_mean & 19.3 & 6.4 & 17.2 & 4.8 & 17.0 & 5.9 & 1.218 & 0.302 & 0.034 \\
\hline
\end{tabular}

Note. $r$ TG = regular users; iTG = irregular users; rCG = randomized controls; t0_GRIP_mean = mean grip strength of all attempts from both hands at first test date. t1_GRIP_mean and t2_GRIP_mean 30CR correspondingly results of subsequent tests. Data presented as kilogram to the nearest tenth. $p=0.05$.

Pairwise comparisons found the difference in t1 to be between rTG and iTG at $p=0.036(0.25 ; 9.0)$ as well as between rTG and rCG at $p=0.025,95 \%$ CI $(0.44 ; 8.0)$.

Two-way ANCOVA (adjusted to baseline scores) with repeated measures showed that the intervention elicited no statistically significant changes in GRIP within groups over time, $F(4,136)=1.554, p=0.192, \eta p^{2}=0.044$ and also no significant differences between groups over time, $F(2,68)=0.858, p=0.429, \eta p^{2}=0.025$, but clearly displays the difference at $\mathrm{t} 1$ found in the ANOVA (see Figure 3). 


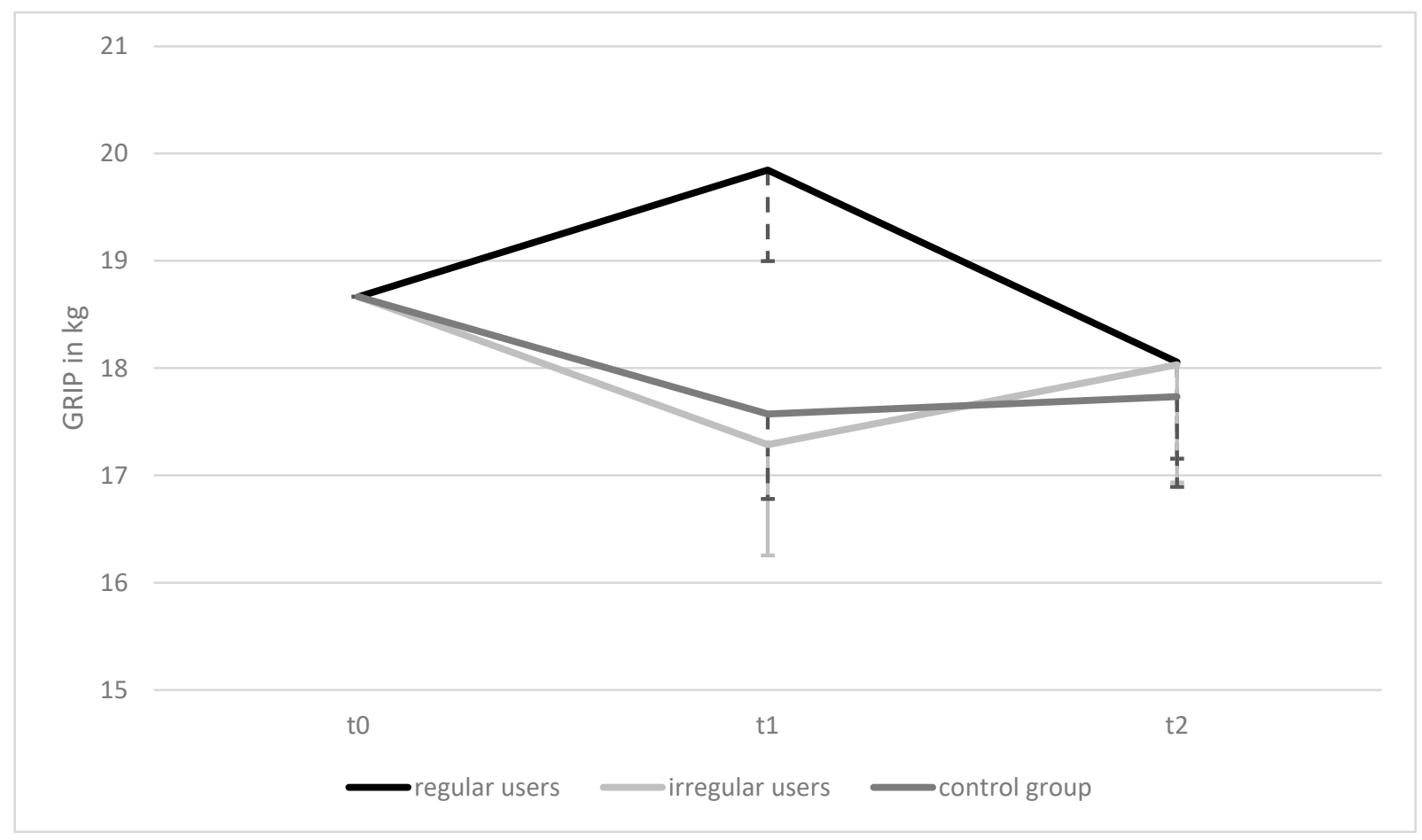

Figure 3. Mean Differences in GRIP ANCOVA Results, Over Time and Between Groups/GRIP = mean grip strength of all attempts from both hands. Data presented as means of all attempts per test date on all three test dates adjusted for baseline values. Error bars (one-sided): 95\% CI.

\subsection{Effects on Lower-Body Strength Measured by 30CR}

The Friedman test revealed no significant changes within groups in $30 \mathrm{CR}$ over the course of the intervention regardless of which group is considered.

Significant differences between groups in median scores were found at all times via Kruskal-Wallis $\mathrm{H}$ test and post hoc analysis revealed statistically significant differences in 30CR between rTG and rCG at all times (see Table 4).

Table 4. Differences in 30CR Between Groups at Times.

\begin{tabular}{|c|c|c|c|c|c|}
\hline \multirow{2}{*}{$30 \mathrm{CR}$, cts } & \multirow{2}{*}{$\begin{array}{c}\text { rTG } \\
n=26\end{array}$} & \multirow{2}{*}{$\begin{array}{c}\text { iTG } \\
n=17\end{array}$} & \multirow{2}{*}{$\begin{array}{c}\text { rCG } \\
n=29\end{array}$} & \multicolumn{2}{|c|}{ Kruskal-Wallis } \\
\hline & & & & $\chi^{2}(2)$ & $p_{a d j}$ \\
\hline t0_30CR & 10.5 & 10.0 & 5.0 & 9.580 & 0.008 \\
\hline t1_30CR & 12.0 & 9.0 & 7.0 & 6.666 & 0.036 \\
\hline t2_30CR & 13.5 & 10.0 & 5.0 & 13.645 & 0.001 \\
\hline
\end{tabular}

Note. $\mathrm{t} 0 \_30 \mathrm{CR}=$ results of the 30 Seconds Chair Rise test on the first test date; $t 1 \_30 \mathrm{CR}$ and $\mathrm{t} 2$ _30CR correspondingly results of subsequent tests. $\mathrm{rTG}=$ regular users; $\mathrm{iTG}=$ irregular users; $\mathrm{rCG}=$ randomized controls. Data presented as counts. $p<0.05$.

Pairwise comparisons revealed significant differences between rTG and rCG at baseline $(p=0.008, r=0.41)$, as well as at $\mathrm{t} 1(p=0.034, r=0.34)$ and at $\mathrm{t} 2(p=0.001, r=0.50)$, but no other differences between groups.

Non-Parametric two-way ANCOVA (corrected for baseline scores) with repeated measures showed that the intervention elicited statistically significant changes in $30 \mathrm{CR}$ scores within groups over time, $F(4,138)=2.695, p=0.033, \eta \mathrm{p}^{2}=0.072$ and a trend for differences between groups over time, $F(2,69)=2.658, p=0.077, \eta p^{2}=0.072$ (see Figure 4). Post hoc testing showed a significant mean difference between rTG and iTG at $p=0.008$ but no other effects. 


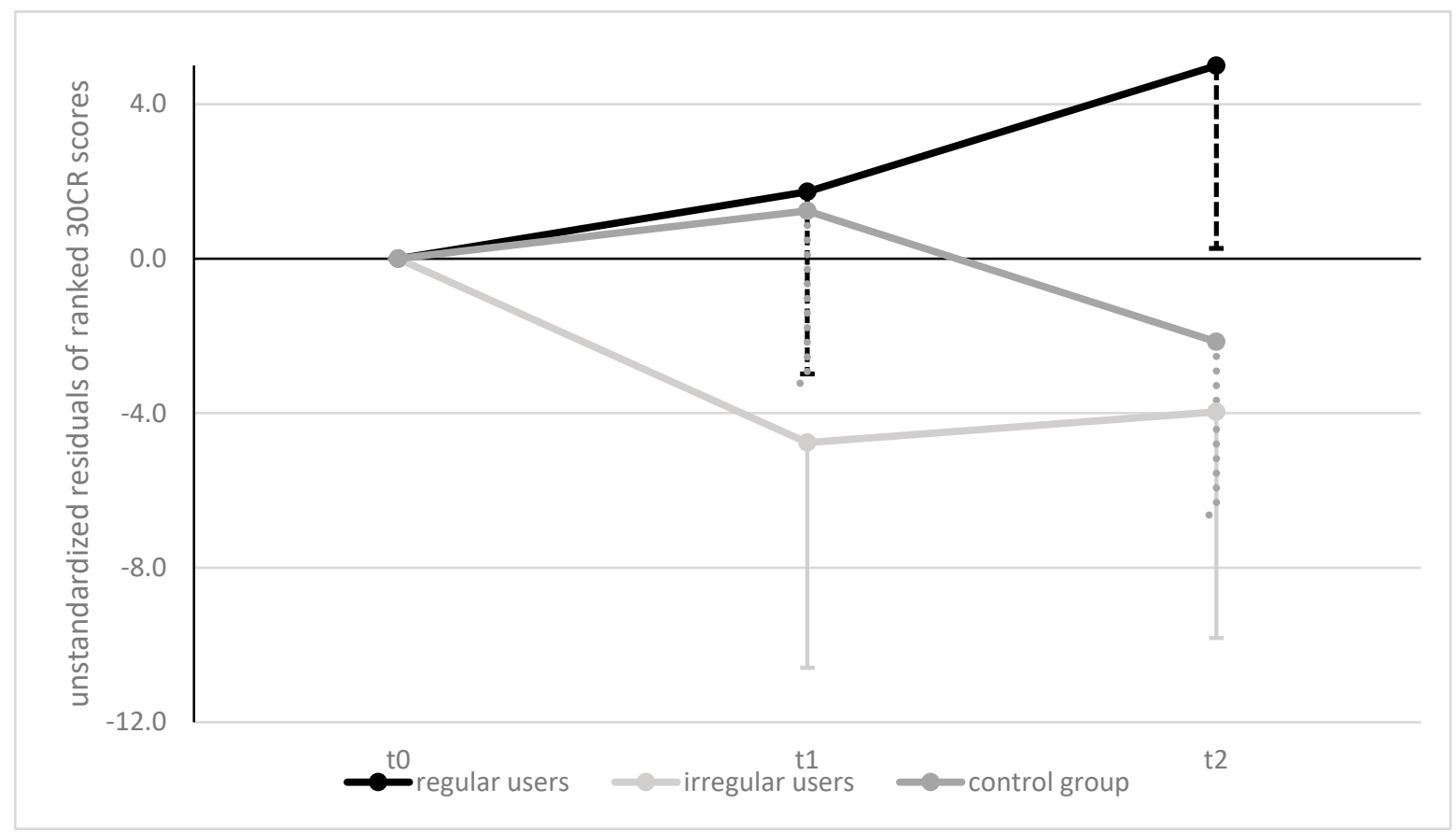

Figure 4. Mean Differences in 30CR ANCOVA Results, Over Time and Between Groups/30CR = 30 Seconds Chair Rise test. Data presented as unstandardized residuals of ranked scores on all three test dates adjusted for baseline scores. Error bars (one-sided): 95\% CI.

\subsection{Effects on Balance Measured by UPS}

Analysis of differences within groups over time, via Friedman test, showed significant differences in rTG, $\chi^{2}(2)=6.320, p=0.042$, and iTG, $\chi^{2}(2)=10.082, p=0.06$, but not in $\mathrm{rCG}, \chi^{2}(2)=0.840, p=0.657$, whereas pairwise comparisons revealed the drop from t0 to t1 scores in iTG being statistically significant $\left(p_{a d j}=0.024, r=0.22\right)$.

Kruskal-Wallis testing showed a significant difference at $t 1$ between groups (see Table 5). Pairwise comparisons revealed significant differences between rTG and rCG at t1 ( $p=0.017, r=0.37$ ), but no other differences at times between groups.

Table 5. Differences in UPS Between Groups at Times.

\begin{tabular}{cccccc}
\hline \multirow{2}{*}{ UPS, sec } & rTG & iTG & rCG & \multicolumn{2}{c}{ Kruskal-Wallis } \\
& $\boldsymbol{n}=\mathbf{2 6}$ & $\boldsymbol{n = 1 7}$ & $\boldsymbol{n = 2 9}$ & $\boldsymbol{\chi}^{\mathbf{2}} \mathbf{( 2 )}$ & $\boldsymbol{p}_{\text {adj }}$ \\
\cline { 2 - 6 } & $\boldsymbol{M} \boldsymbol{d} \boldsymbol{n}$ & $\boldsymbol{M} \boldsymbol{d} \boldsymbol{n}$ & $\boldsymbol{M} \boldsymbol{d} \boldsymbol{n}$ & 2.604 & 0.272 \\
t0_UPS & 5.8 & 8.0 & 0.0 & 8.589 & 0.014 \\
t1_UPS & 15.0 & 2.0 & 0.0 & 4.290 & 0.117 \\
t2_UPS & 11.0 & 8.0 & 0.0 & \\
\hline
\end{tabular}

Note. t0_UPS $=$ results of the Unipedal stance test on the first test date; $t 1 \_U P S$ and t2_UPS correspondingly results of subsequent tests; rTG = regular users; iTG = irregular users; rCG = randomized controls. Data presented as counts. $p<0.05$.

Figure 5 presents results of the nonparametric two-way ANCOVA (corrected for baseline scores) with repeated measures. The analysis showed that the intervention elicited statistically significant changes in UPS scores within groups over time, $F(4,138)=4.506$, $p=0.008, \eta p^{2}=0.116$ and also for differences between groups over time, $F(2,69)=4.279$, $p=0.018, \eta p^{2}=0.110$. Post hoc testing showed a significant difference between rTG and iTG at $p=0.03$ and a trend towards difference between rTG and rCG at $p=0.093$. 


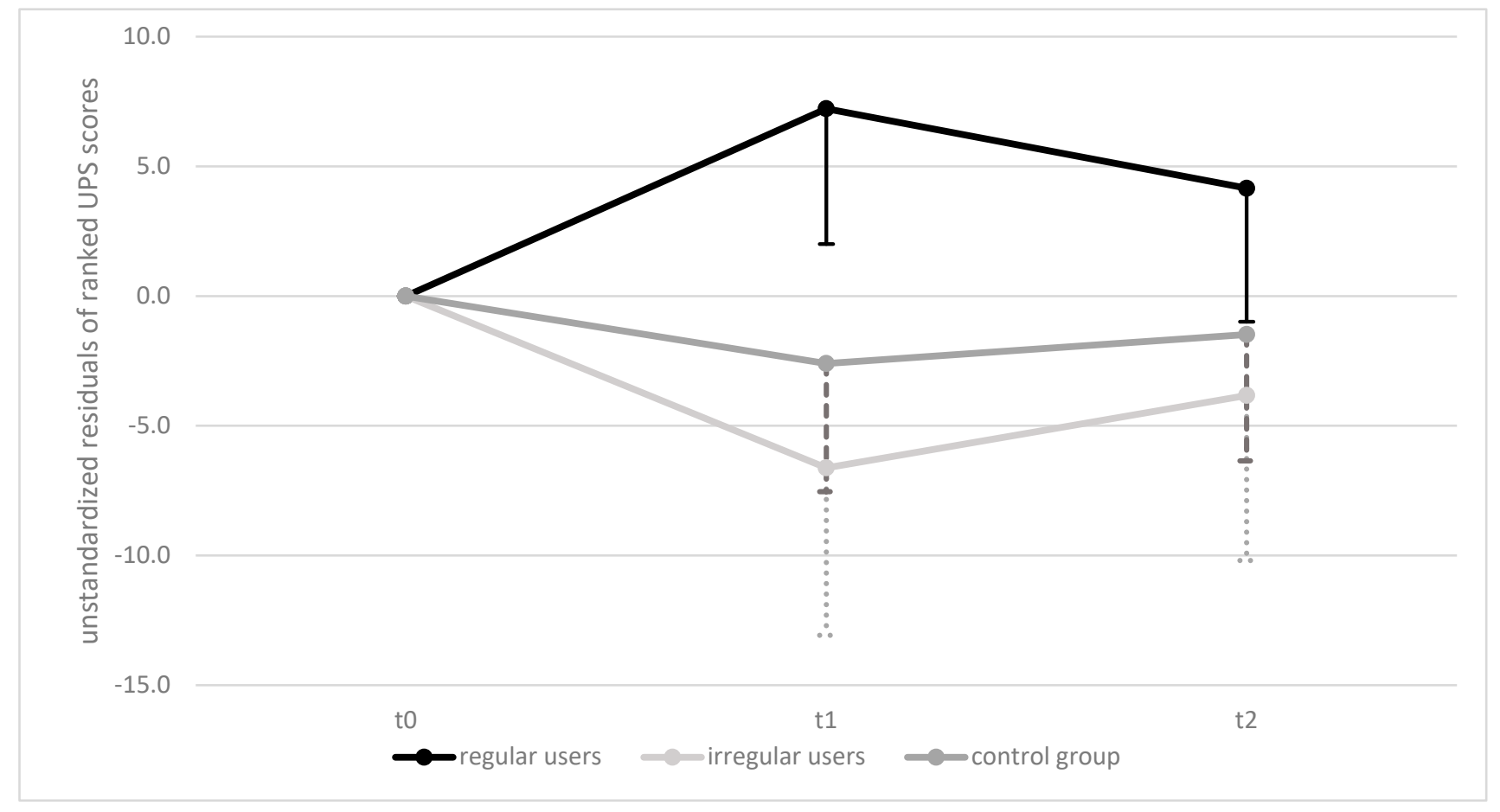

Figure 5. Mean Differences in UPS ANCOVA Results, Over Time and Between Groups/UPS = Uni Pedal Stance. Data presented as unstandardized residuals of ranked UPS scores on all three test dates adjusted for baseline scores. Error bars (one-sided): $95 \%$ CI.

\section{Discussion}

Supporting older people, especially HCSU, to prevent physical decline [44] is more important than ever. It is especially important for women who are already in need of care to stay active, as they have lower fitness levels than their independently living peers and their abilities decline sharply without physical engagement [45]. As technological capabilities continue to increase, it is necessary to consider whether they can be used as potent tools for keeping HCSU fit. The objective of the study was to determine whether an unsupervised, functional ICT-mediated exercise program, with a minimum use of two times per week, has positive effects on the development of strength and balance in older, female HCSUs, compared with those who use the program less frequently or do not have access to the program. The data show that the studied training program increased fitness in regular users, which is in line with the outcome of other ICT-exercise programs [46].

Sixty percent of the here-investigated TG used the FFP at least eight times per month, according to the usage evaluation [19]. Compared with other eHealth interventions, which are typically designed for once-a-week use and achieved adherence of about $50 \%$, this intervention exhibited a remarkably high adherence rate [47]. In terms of adherence rate, our intervention was also superior to a comparable supervised program consisting of 32 one-hour sessions over six months, where only 19 of 40 subjects $(48 \%)$ completed a sufficient number of sessions, indicating a lower adherence rate compared with our ICT program [48]. However, a low adherence rate is not unusual. It is estimated that exercise programs for older people have a drop-out rate of about half within the first 6 months [49] and adherence is typically reported to be poor for exercise programs [50]. The brevity of the training sessions and the strength training components could be reasons for this good adherence rate. The latter was found to elicit higher adherence rates compared to endurance training in general [51]. Moreover, it could also speak for the design of both the user interface of the app as well as the intervention itself. Our data show that a nonsupervised exercise program can achieve adequate adherence rates among female HCSUs when delivered via ICT and thus can have an influence on physical fitness. 
Grip strength, which serves as a surrogate for overall strength [26] was affected by our intervention especially over the first period. The results of the rTG at t1 point towards better strength of the subjects who used the application regularly compared to the iTG and CG. The reason that this effect did not last until the end of the trial may be attributed to the fact that due to the brevity of the sessions, the program focused on lower-body strengthening as well as balance, thus upper-body dominant exercises were less represented. It is likely that this parameter would have needed a more extensive training program to experience sustained increases. This finding is consistent with the results of the Lifestyle Interventions and Independence for Elders (LIFE) study [52], which assessed grip strength at 6-month intervals over a period of 36 months, among other measures. Although markers such as the Short Physical Performance Battery (SPPB) score or the $30 \mathrm{~s}$ chair rise test were improved, there was no increase in grip strength measured either. Similar to our study, this was attributed to the focus of the training program, which addressed lower extremities.

Lower-body strength expressed as $30 \mathrm{~s}$ chair rise ability increased in those who used the FFP regularly and decreased with low usage or in controls. This finding is consistent with existing results demonstrating that lower-body strength, measured via $30 \mathrm{~s}$ chair rise in care-using women, significantly decreases over 8 months due to insufficient activity without intervention [45]. Our data underline the positive effect of the program on the lower-body strength of those who have used the application at least twice a week (see Figure 3). These results fit well with the recommendations for health-promoting physical activity, which recommend total body strengthening at least twice a week [3]. It has already been studied, that implementing these recommendations in a supervised setting leads to more lower-body strength in care-users [16] as well as in community-dwelling adults $[45,52]$. Now we have preliminary evidence that improvement of this parameter is also possible with ICT-mediated training programs.

As balance can be seen as a potent precursor of improvements in other motor abilities, the increase of $30 \mathrm{CR}$ scores may be attributed to improved balance ability [53,54]. Static balance ability increased in the first six months of intervention and dropped slightly above baseline within the rTG (see Figure 4), which is consistent with findings where an improvement was achieved within the first few months, followed by a slight reduction in balance performance in the subsequent months [52]. However, in our study, the values dropped significantly in those who started at reasonably good levels (iTG) but did not use the system regularly. In CG, which began at an extremely poor level, the deterioration in balance ability progressed to the point where at least half of the group could not stand on one leg for a single second. Thus, the training program studied had positive effects on balance over 8 months as it was able to counteract degradation in balance performance.

In light of these findings, we emphasize the importance of regular physical training for female HCSUs, highlighting that even short training sessions can produce positive effects for this group of individuals, and note that this can be achieved by an unsupervised ICT-mediated fitness program. The strength of our study is that we measured the effects under normal field conditions [55] with valid indicators for all outcomes [25,26,28,29] and a good adherence rate over a long-term course of eight months. Participants who regularly followed the FFP maintained their strength and balance at baseline levels or showed improvements compared to their peers. Despite similar baseline levels, participants who did not follow the FFP regularly showed a decrease in bodily functions over the course of eight months that was similar to the trends in the control group.

Due to the small sample size, a problem that is often the case in such study settings [46], the results should be treated with caution with regard to their generalizability. The study was not completely randomized because HCSUs had the right to decline assignment to any of the groups, which correspondingly affects the external validity of the results. The automatically logged usage data provide insight into time and frequency of use, without evidence of actual exercise performance or an assessment of exercise quality. 


\section{Conclusions}

In conclusion, the ICT-assisted fitness training examined in this study can be well applied to counteract losses in strength and balance in female HCSUs aged 60 to 91 years with low support needs. Adherence rates indicate that this new way of training is well accepted by females of age who want to maintain their physical condition, when designed to their needs.

Author Contributions: Conceptualization, S.J. and S.R.-D.; formal analysis, S.J.; investigation, S.J.; data curation, S.J., C.S.; writing — original draft preparation, S.J.; writing—review and editing, S.R.-D., B.T., S.E., C.S.; visualization, S.J.; supervision, S.R.-D.; project administration, C.S.; funding acquisition, C.S. All authors have read and agreed to the published version of the manuscript.

Funding: This work was supported by the Active Assisted Living Programme grant number AAL 2014-1-021. It received funding from the Active Assisted Living Programme, cofounded by the European Commission, National Funding Authorities of Austria, Italy, and Switzerland, and the individual project partners. Collaborating partners in the CiM project were Salzburg Research Forschungsgesellschaft m.b.H. (lead partner), Vienna University of Economics and Business, Paris Lodron University of Salzburg, ilogs mobile software GmbH, bit media e-solutions $\mathrm{GmbH}$, ALDIA Cooperativa Sociale, Hilfswerk Salzburg, and Eichenberger-Szenografie. The CiM project ran from October 2015 until September 2018. The Research Institute for Economics of Aging at the Vienna University of Economics and Business received additional funding from the Social Fund Vienna (FSW).

Institutional Review Board Statement: The parent project CiM was approved by the Ethics Committee of the Paris Lodron University of Salzburg (EK-GZ:30/2016). Field testing was conducted in Austria and Italy.

Informed Consent Statement: Informed consent was obtained from all subjects involved in the study.

Data Availability Statement: The data presented in this study are available on request from the corresponding author. The data are not publicly available due to privacy.

Conflicts of Interest: The authors certify that they have no affiliations with or involvement in any organization or entity with any financial interest or non-financial interest in the subject matter or materials discussed in this manuscript.

\section{References}

1. $\quad$ Rikli, R.E.; Jones, C.J. Senior Fitness Test Manual; Human Kinetics: Champaign, IL, USA, 2013.

2. Bray, N.W.; Smart, R.R.; Jakobi, J.M.; Jones, G.R. Exercise prescription to reverse frailty. Appl. Physiol. Nutr. Metab. 2016, 41, 1112-1116. [CrossRef] [PubMed]

3. WHO. Global Recommendations on Physical Activity for Health; World Health Organization: Geneva, Switzerland, 2010.

4. Piercy, K.L.; Troiano, R.P.; Ballard, R.M.; Carlson, S.A.; Fulton, J.E.; Galuska, D.A.; George, S.M.; Olson, R.D. The Physical Activity Guidelines for Americans. JAMA 2018, 320, 2020-2028. [CrossRef] [PubMed]

5. Bushman, B.A. Physical Activity Guidelines for Americans: The Relationship Between Physical Activity and Health. ACSM Health Fit. J. 2019, 23, 5-9. [CrossRef]

6. Chodzko-Zajko, W.J.; Proctor, D.N.; Singh, M.A.F.; Minson, C.T.; Nigg, C.R.; Salem, G.J.; Skinner, J.S. Exercise and Physical Activity for Older Adults. Med. Sci. Sports Exerc. 2009, 41, 1510-1530. [CrossRef]

7. Muellmann, S.; Forberger, S.; Möllers, T.; Bröring, E.; Zeeb, H.; Pischke, C.R. Effectiveness of eHealth interventions for the promotion of physical activity in older adults: A systematic review. Prev. Med. 2018, 108, 93-110. [CrossRef]

8. Lacroix, A.; Kressig, R.W.; Muehlbauer, T.; Gschwind, Y.J.; Pfenninger, B.; Bruegger, O.; Granacher, U. Effects of a Supervised versus an Unsupervised Combined Balance and Strength Training Program on Balance and Muscle Power in Healthy Older Adults: A Randomized Controlled Trial. Gerontology 2015, 62, 275-288. [CrossRef] [PubMed]

9. Elbert, N.J.; Van Os-Medendorp, H.; Van Renselaar, W.; Ekeland, A.G.; Roijen, L.H.-V.; Raat, H.; Nijsten, T.E.C.; Pasmans, S.G.M. Effectiveness and Cost-Effectiveness of eHealth Interventions in Somatic Diseases: A Systematic Review of Systematic Reviews and Meta-Analyses. J. Med. Internet Res. 2014, 16, e110. [CrossRef]

10. WHO. Decade of Healthy Ageing: Baseline Report; World Health Organization: Geneva, Switzerland, 2020.

11. Murtagh, K.N.; Hubert, H.B. Gender Differences in Physical Disability Among an Elderly Cohort. Am. J. Public Health 2004, 94, 1406-1411. [CrossRef] [PubMed]

12. Suzuki, M.; Ohyama, N.; Yamada, K.; Kanamori, M. The relationship between fear of falling, activities of daily living and quality of life among elderly individuals. Nurs. Health Sci. 2002, 4, 155-161. [CrossRef] 
13. Frontini, R.; Sousa, P. Exploring healthcare professionals' acceptance towards ICT-based interventions for health promotion: A mixed-methods approach. Eur. J. Public Health 2019, 29. [CrossRef]

14. Nogueira, A.C.; Resende-Neto, A.; Santos, A.J.; Chaves, L.d.S.; Azevêdo, L.; Teixeira, C.; Senna, G.; Da Silva-Grigoletto, M. Effects of a multicomponent training protocol on functional fitness and quality of life of physically active older women. Motricidade 2017, $13,86-93$.

15. De Resende-Neto, A.; do Nascimento, M.A.; Aragão-Santos, J.C.; Andrade, B.C.O.; Vasconcelos, A.B.S.; da Silva, D.R.P.; Netto, R.S.M.; de Santana, J.M.; Grigoletto, M.E.D.S. Effects of Multicomponent Training on Functional Fitness and Quality of Life in Older Women: A Randomized Controlled Trial. Int. J. Sport. Exerc. Med. 2019, 5. [CrossRef]

16. Sousa, N.; Mendes, R.; Silva, S.; Garrido, N.; Abrantes, C.; Reis, V. Effects of Resistance and Multicomponent Training on Body Composition and Physical Fitness of Institutionalized Elderly Women. Br. J. Sports Med. 2013, 47, e3.48. [CrossRef]

17. Trukeschitz, B.; Blüher, M. Measuring the Effectiveness of 'CARIMO', an ICT-Supported Fitness and Entertainment App for Home Care Recipients: Study Protocol and Survey Data Collection; Vienna University of Economics and Business (WU): Vienna, Austria, 2018.

18. Rossi, P.H.; Lipsey, M.W.; Freeman, H.E. Evaluation: A Systematic Approach; Sage: Newbury Park, CA, USA, 2004.

19. Schneider, C.; Trukeschitz, B.; Rieser, H. Measuring the Use of the Active and Assisted Living Prototype CARIMO for Home Care Service Users: Evaluation Framework and Results. Appl. Sci. 2019, 10, 38. [CrossRef]

20. Prochaska, O.J.; DiClemente, C.C. Stages and processes of self-change of smoking: Toward an integrative model of change. J. Consult. Clin. Psychol. 1983, 51, 390. [CrossRef] [PubMed]

21. Lesinski, M.; Hortobágyi, T.; Muehlbauer, T.; Gollhofer, A.; Granacher, U. Dose-Response Relationships of Balance Training in Healthy Young Adults: A Systematic Review and Meta-Analysis. Sports Med. 2015, 45, 557-576. [CrossRef] [PubMed]

22. Cadore, E. Strength and Endurance Training Prescription in Healthy and Frail Elderly. Aging Dis. 2014, 5, 183-195. [CrossRef]

23. Garber, C.E.; Blissmer, B.; Deschenes, M.R.; Franklin, B.A.; Lamonte, M.J.; Lee, I.-M.; Nieman, D.C.; Swain, D.P. Quantity and Quality of Exercise for Developing and Maintaining Cardiorespiratory, Musculoskeletal, and Neuromotor Fitness in Apparently Healthy Adults: Guidance for Prescribing Exercise. Med. Sci. Sports Exerc. 2011, 43, 1334-1359. [CrossRef]

24. WHO. Physical Status: The Use of snd Interpretation of Anthropometry, Report of a WHO Expert Committee; World Health Organization: Geneva, Switzerland, 1995.

25. Bohannon, R.W. Hand-Grip Dynamometry Predicts Future Outcomes in Aging Adults. J. Geriatr. Phys. Ther. 2008, 31, 3-10. [CrossRef]

26. Bohannon, R.W. Grip Strength: An Indispensable Biomarker For Older Adults. Clin. Interv. Aging 2019, 14, 1681-1691. [CrossRef]

27. Massy-Westropp, N.M.; Gill, T.K.; Taylor, A.W.; Bohannon, R.W.; Hill, C.L. Hand Grip Strength: Age and gender stratified normative data in a population-based study. BMC Res. Notes 2011, 4, 127. [CrossRef]

28. JJones, C.J.; Rikli, R.E.; Beam, W.C. A 30-s Chair-Stand Test as a Measure of Lower Body Strength in Community-Residing Older Adults. Res. Q. Exerc. Sport 1999, 70, 113-119. [CrossRef]

29. Springer, B.A.; Marin, R.; Cyhan, T.; Roberts, H.; Gill, N.W. Normative Values for the Unipedal Stance Test with Eyes Open and Closed. J. Geriatr. Phys. Ther. 2007, 30, 8-15. [CrossRef]

30. Rusticus, S.A.; Lovato, C.Y. Impact of sample size and variability on the power and type I error rates of equivalence tests: A simulation study. Pract. Assess. Res. Eval. 2014, 19, 11.

31. Gogtay, N.; Thatte, U. Principles of correlation analysis. J. Assoc. Physicians India 2017, 65, 78-81.

32. Scheffé, H. The Analysis of Variance, 6th ed.; Wiley \& Sons, Inc.: Hoboken, NJ, USA, 1970.

33. Kruskal, W.H.; Wallis, W.A. Use of ranks in one-criterion variance analysis. J. Am. Stat. Assoc. 1952, 47, 583-621. [CrossRef]

34. Friedman, M. The use of ranks to avoid the assumption of normality implicit in the analysis of variance. J. Am. Stat. Assoc. 1937, 32, 675-701. [CrossRef]

35. Dunn, O.J. Multiple comparisons using rank sums. Technometrics 1964, 6, 241-252. [CrossRef]

36. Conover, W.J.; Iman, R.L. Analysis of Covariance Using the Rank Transformation. Biometrics 1982, 38, 715-724. [CrossRef]

37. Gignac, G.; Szodorai, E.T. Effect size guidelines for individual differences researchers. Personal. Individ. Differ. 2016, 102, 74-78. [CrossRef]

38. Cohen, J. Statistical Power Analysis for the Behavioral Sciences, 2nd ed.; Lawrence Erlbaum Associates Inc.: Mahwah, NJ, USA, 1988; p. 13.

39. WHO. Obesity and Overweight. Fact Sheet No. 311. January 2015. Available online: http://www.who.int/mediacentre/ factsheets/fs311/en/Stand (accessed on 20 January 2020).

40. Greve, J.M.D.; Alonso, A.C.; Bordini, A.C.P.; Camanho, G.L. Correlation between body mass index and postural balance. Clinics 2007, 62, 717-720. [CrossRef]

41. Schmid, S.; Armand, S.; Pataky, Z.; Golay, A.; Allet, L. The Relationship Between Different Body Mass Index Categories and Chair Rise Performance in Adult Women. J. Appl. Biomech. 2013, 29, 705-711. [CrossRef] [PubMed]

42. Dodds, R.; Syddall, H.E.; Cooper, R.; Benzeval, M.; Deary, I.; Dennison, E.; Der, G.; Gale, C.; Inskip, H.; Jagger, C.; et al. Grip Strength across the Life Course: Normative Data from Twelve British Studies. PLoS ONE 2014, 9, e113637. [CrossRef] [PubMed]

43. Rikli, R.E.; Jones, C.J. Functional Fitness Normative Scores for Community-Residing Older Adults, Ages 60-94. J. Aging Phys. Act. 1999, 7, 162-181. [CrossRef] 
44. Brach, J.S.; FitzGerald, S.; Newman, A.B.; Kelsey, S.; Kuller, L.; VanSwearingen, J.M.; Kriska, A.M. Physical activity and functional status in community-dwelling older women: A 14-year prospective study. Arch. Intern. Med. 2003, 163, 2565-2571. [CrossRef] [PubMed]

45. Furtado, H.; Sousa, N.; Simão, R.; Pereira, F.; Vilaça-Alves, J. Physical exercise and functional fitness in independently living vs institutionalized elderly women: A comparison of 60- to 79-year-old city dwellers. Clin. Interv. Aging 2015, 10, 795-801.

46. Yerrakalva, D.; Yerrakalva, D.; Hajna, S.; Griffin, S. Effects of Mobile Health App Interventions on Sedentary Time, Physical Activity, and Fitness in Older Adults: Systematic Review and Meta-Analysis. J. Med. Internet Res. 2019, 21, e14343. [CrossRef]

47. Kelders, S.M.; Kok, R.; Ossebaard, H.C.; Van Gemert-Pijnen, J.E. Persuasive System Design Does Matter: A Systematic Review of Adherence to Web-based Interventions. J. Med. Internet Res. 2012, 14, e152. [CrossRef]

48. Bastone, A.; Filho, W.J. Effect of an exercise program on functional performance of institutionalized elderly. J. Rehabil. Res. Dev. 2004, 41, 659. [CrossRef] [PubMed]

49. Chao, D.; Foy, C.G.; Farmer, D. Exercise Adherence among Older Adults: Challenges and Strategies. Control. Clin. Trials 2000, 21, S212-S217. [CrossRef]

50. Dishman, R.K. Increasing and maintaining exercise and physical activity. Behav. Ther. 1991, 22, 345-378. [CrossRef]

51. Picorelli, A.; Sirineu, D.; Felício, D.; Anjos, D.; Gomes, D.; Dias, R.; Pereira, D.; Assis, M.G. Adherence of older women with strength training and aerobic exercise. Clin. Interv. Aging 2014, 9, 323-331. [CrossRef]

52. Santanasto, A.; Glynn, N.W.; Lovato, L.C.; Blair, S.N.; Fielding, R.A.; Gill, T.M.; Guralnik, J.M.; Hsu, F.; King, A.C.; Strotmeyer, E.S.; et al. Effect of Physical Activity versus Health Education on Physical Function, Grip Strength and Mobility. J. Am. Geriatr. Soc. 2017, 65, 1427-1433. [CrossRef] [PubMed]

53. Hrysomallis, C. Balance Ability and Athletic Performance. Sports Med. 2011, 41, 221-232. [CrossRef] [PubMed]

54. Lord, S.R.; Murray, S.M.; Chapman, K.; Munro, B.; Tiedemann, A. Sit-to-Stand Performance Depends on Sensation, Speed, Balance, and Psychological Status in Addition to Strength in Older People. J. Gerontol. Ser. A 2002, 57, M539-M543. [CrossRef] [PubMed]

55. Victora, C.; Habicht, J.-P.; Bryce, J. Evidence-Based Public Health: Moving Beyond Randomized Trials. Am. J. Public Health 2004, 94, 400-405. [CrossRef] 